\title{
Recurrent Parotid Gland Squamous Cell
} Carcinoma

National Cancer Institute

\section{Source}

National Cancer Institute. Recurrent Parotid Gland Squamous Cell Carcinoma. NCI

Thesaurus. Code C153810.

The reemergence of parotid gland squamous cell carcinoma after a period of remission. 